www.jmscr.igmpublication.org

Impact Factor 5.84

Index Copernicus Value: 83.27

ISSN (e)-2347-176x ISSN (p) 2455-0450

crossref DOI:_https://dx.doi.org/10.18535/jmscr/v5i2.155

Journal Of Medical Science And Clinical Research

\title{
Prevalence of Dry Eye Diseases in the Out Patient Department of ophthalmology in a tertiary care center
}

\author{
Authors \\ Atul Raut MS, Dhiraj Lambat* DOMS \\ Ophthalmology Department, Government Medical College, Nanded \\ *Corresponding Author \\ Dhiraj Lambat DOMS \\ Junior Resident, Ophthalmology Department, Government Medical College, Nanded \\ Email:drdhirajlambat@gmail.com
}

\begin{abstract}
Background: Around the world it is learnt that between 5-34\% of people have some form at dry eye and prevalence significantly increases with age ${ }^{[4,5]}$ The large variation in the prevalence of dry eye disease is attributed to the variations in the study population, geographical differences and lack of uniformity in method and definitions of the disease dry eye.

Patients and Methods: during the period from July 2015 to Nov-2016 Patients were consecutively selected and underwent a routine ophthalmological examination along with tear film break-up time (TBUT), Schimers test and Rose Bengal test or flourescien staining as a screening tools for detecting the presence of dry eye. Statistical Analysis: Data are expressed as mean, standard deviation and range. For quantitative data, statistical evaluations are performed by using t test and for qualitative data chi square test is used.

Results: A total of 500 patients were screened for dry eye in Department of Ophthalmology in the tertiary care center. Out of these 82 patients were diagnosed as having dry eye. For the study factors such as age, sex, occupation, responsible diseases and season were taken into consideration.

Conclusion: our study showed that the prevalence of dry eye disease is very high among the elderly female. The overall prevalence dry eye was found to be $16.4 \%$. and it was also found that dry eye disease is under diagnosed disorder.
\end{abstract}

\section{Introduction}

Dry Eye Diseases is one of the most frequently encountered clinical diagnosis in ophthalmic practice. Dry eye's is one of the conditions seen at all levels of ophthalmic care.

In 2007, the International Dry Eye Workshop (DEWS) revised the original definition and classification scheme of dry eye disease (DED) and developed a new definition based on etiology, mechanism, and severity of the disease. The term dry-eye syndrome according to DEWS has been defined as "a multi-factorial disease of the tears and ocular surface that results in symptoms of discomfort, visual disturbance, and tear-film instability with potential damage to the ocular surface. It is accompanied by increased osmolarlity of the tear film and inflammation of the ocular surface". ${ }^{1}$ Dry eye refers to disorders of the tear film due to reduced tear production and/or excessive tear evaporation associated with symptoms of ocular discomfort. ${ }^{2}$

Dry eye impairs functional vision; especially during 
reading, driving, using computers, and mobile phones ${ }^{[3,4,5,6]}$. Reading speed for instance is significantly reduces at positively correlates and with dry eye disease severity. ${ }^{[3]}$

The psychological problems associated with highly symptomatic, incurable, Chronic disease can required considerable support .Quality-of-life studies have shown that impact of moderate to severe dry eye is similar to that of moderate to severe angina. ${ }^{[7]}$

Dry eye is chronic disease ${ }^{[8]}$ which may have substantial impact on patient's quality of life.

\section{Patients and Methods}

During the period from July 2015 to Nov-2016 Patients were consecutively selected and underwent a routine ophthalmological examination along with tear film break-up time (TBUT), Schimers test and Rose Bengal test or flouroscien staining as a screening tools for detecting the presence of dry eye. Statistical Analysis: Data are expressed as mean, standard deviation and range. For quantitative data, statistical evaluations are performed by using $t$ test and for qualitative data chi square test is used.

Detailed ocular history was taken. Special emphasis given over history of using any ocular medication and also using medication especially for dry eyes. Whether the patients have maximal complaints early in morning or at the end of the day or at the end of the work are asked.

Medical history which may be significant for coexisting connective tissue disease, rheumatoid arthritis, or thyroid abnormalities is also asked. Analysis was done to find out prevalence of dry eye symptoms and its risk factor. For this analysis factors such as age, sex, occupation, responsible diseases and season are taken into consideration.

The cut off value for Schirmer's test is $15 \mathrm{~mm}$ at the end of the $5 \mathrm{~mm}$. (Reddy M 1991) ${ }^{9}$

The intensity of the Rose Bengal staining of the cornea and conjunctiva on the zone was recorded, with a possible minimum score being 0 and a possible maximum score being 3 on each nasal conjunctiva, cornea, and temporal conjunctiva

Van Bjisterveld scoring system ${ }^{10}$

Minimum score 0

Maximum score 9

Dry eye $>4$

Flurescein staining of the cornea was also rated, with a possible minimum score being 0 and a possible maximum score being 3 on each upper, central, and lower cornea. ${ }^{10}$

A normal TBUT is more than 10 seconds and a TBUT of less than 10second is considered abnormal ${ }^{11.12 .13}$ The break-up time was noted in seconds. The mean of the three readings were taken as the final TBUT. If the film broke-up at the same location all the three times, this spot was ignored as this was indicative of local epithelial defect or a come-al surface abnormality and not as an intrinsic instability of the precorneal tear film.

First 300 patients in study were screened in winter and next 200 were screened in summer season.

\section{Inclusion Criteria:}

Patients presenting in ophthalmology Out Patient Department above the age of 5 years with various ophthalmic complaints.

\section{Exclusion Criteria}

1. Patients suffering from ocular infections.

2. Patients who undergone extra-ocular and intraocular surgery.

3. Patients already diagnosed and using medications for dry eye.

4. Patients less than 5 years of age

\section{Analysis of data}

Data are expressed as mean, standard deviation and range. For quantitative data, statistical evaluations are performed by using $\mathrm{t}$ test and for qualitative data chi square test is used.

\section{RESULTS AND OBSERVATIONS}

A total of 500 patients were screened for dry eye in Department of Ophthalmology in the tertiary care center. Out of these 82 patients were diagnosed as having dry eye. For the study factors such as age, sex, occupation, responsible diseases and season were taken into consideration. 
Table 1 : Distribution of Patients according to Age

\begin{tabular}{|l|c|c|c|c|}
\hline $\begin{array}{l}\text { Age Group } \\
\text { (Years) }\end{array}$ & \multicolumn{2}{|c|}{ No of Patients (n) } & \multirow{2}{*}{$\begin{array}{c}\text { Patients } \\
\text { with Dry } \\
\text { Eye (n) }\end{array}$} & $\begin{array}{c}\text { Percentage } \\
(\%)\end{array}$ \\
\hline $5-10$ & Male & Female & 4 & $21.05 \%$ \\
\hline $11-20$ & 10 & 9 & 4 & $7.69 \%$ \\
\hline $21-30$ & 28 & 24 & 9 & $15.00 \%$ \\
\hline $31-40$ & 33 & 27 & 14 & $13.86 \%$ \\
\hline $41-50$ & 50 & 51 & 13 & $12.38 \%$ \\
\hline $51-60$ & 54 & 51 & 18 & $17.31 \%$ \\
\hline$>60$ & 50 & 54 & 20 & $33.90 \%$ \\
\hline Total & 30 & 29 & $\mathbf{8 2}$ & $\mathbf{1 6 . 4 \%}$ \\
\hline
\end{tabular}

Total 500 patients were evaluated for the presence of dry eye symptoms. Out of 500 patients 255 were male and 245 were female.

Age wise distribution of patients shows that $21.05 \%$ of patients belong to 5-10 age group, $7.69 \%$ belongs to $11-20$ age group, $15 \%$ belongs to the $21-30$ age group, $13.86 \%$ belongs to the $31-$ 40 age groups, $12.38 \%$ belongs to the $41-50$ age group, $17.31 \%$ belongs to the 51-60 age group and $33.90 \%$ belongs to the $>60$ age group. Difference is statistically significant $(p<0.05)$, indicating that dry eye symptoms are more in elderly patients above 50 years of age.

Table 2 : Distribution of Patients according to Gender

\begin{tabular}{|l|c|c|c|}
\hline Sex & $\begin{array}{c}\text { No. of } \\
\text { Patients }\end{array}$ & $\begin{array}{c}\text { Number of Patients } \\
\text { with Dry Eye (n) }\end{array}$ & Percentage (\%) \\
\hline Male & 255 & 36 & $14.12 \%$ \\
\hline Female & 245 & 46 & $18.78 \%$ \\
\hline Total & $\mathbf{5 0 0}$ & $\mathbf{8 2}$ & $\mathbf{1 6 . 4 \%}$ \\
\hline
\end{tabular}

Gender wise distribution of patients indicates that $14.12 \%$ male and $18.78 \%$ female patients developed dry eye.

The difference is not statistically significant. This indicates prevalence of dry eye is comparable in both sexes.

Table 3: Distribution of Patients with dry eye symptoms according to diseases

\begin{tabular}{|l|c|c|}
\hline Disease & $\begin{array}{c}\text { Number of } \\
\text { Patients with } \\
\text { Dry eye (n) }\end{array}$ & $\begin{array}{c}\text { Percentage } \\
(\%)\end{array}$ \\
\hline Sjogren's Syndrome & 3 & $3.66 \%$ \\
\hline Non Sjogren's Syndrome & 13 & $15.85 \%$ \\
\hline Meibomian gland dysfunction & 16 & $19.51 \%$ \\
\hline Xerophthalmia & 10 & $8.54 \%$ \\
\hline Steven Johnson syndrome & 3 & $3.66 \%$ \\
\hline Computer vision syndrome & 6 & $12.20 \%$ \\
\hline
\end{tabular}

\begin{tabular}{|l|c|c|}
\hline Contact lens related & 5 & $6.10 \%$ \\
\hline Environmental & 10 & $12.20 \%$ \\
\hline Drug induced & 5 & $6.10 \%$ \\
\hline Thyroid disease & 2 & $2.44 \%$ \\
\hline Others & 8 & $9.76 \%$ \\
\hline Total & 82 & $100 \%$ \\
\hline
\end{tabular}

Above table shows 3 patients $(3.66 \%)$ have Sjogrens syndrome, $15.85 \%$ of patients have non - Sjogrens syndrome, $19.51 \%$ has Meibomian gland dysfunction, $8.54 \%$ has xeropthalmia, $3.66 \%$ patients have Steven Jonson syndrome, $12.20 \%$ has computer vision syndrome, $6.10 \%$ has contact lens, $12.20 \%$ patients have environmental causes and $6.10 \%$ and $2.44 \%$ has drug induced and thyroid diseases related dry eye symptoms respectively. This indicates that prevalence of dry eye is more in patients with lid related diseases computer vision syndrome and in those with dry eye because of environmental causes.

Table 4 : Results of Schirmer test and TFBUT test in patients with dry eye.

\begin{tabular}{|l|l|l|l|l|l|}
\hline Disease Condition & \multicolumn{2}{|l|}{$\begin{array}{l}\text { Dry eye } \\
\text { subjects }(\mathrm{n})\end{array}$} & \multicolumn{2}{|l|}{$\begin{array}{l}\text { Schirmer test } \\
(\mathrm{mm})\end{array}$} & \multicolumn{2}{|l|}{ TFBUT (Sec) } \\
\hline & & Mean & Range & Mean & Range \\
\hline $\begin{array}{l}\text { Sjogrens } \\
\text { Syndrome }\end{array}$ & 3 & 3.6 & $3-4$ & 4.8 & $3.8-5$ \\
\hline $\begin{array}{l}\text { Non - Sjogrens } \\
\text { Syndrome }\end{array}$ & 13 & 8.6 & $6-12$ & 5.4 & $4-7$ \\
\hline $\begin{array}{l}\text { Meibomian gland } \\
\text { disfunction }\end{array}$ & 16 & 15.18 & $12-19$ & 4.02 & $2-7$ \\
\hline Xerophthalmia & 7 & 15.4 & $13-18$ & 10.9 & $7-13$ \\
\hline $\begin{array}{l}\text { Steven Jonson } \\
\text { Syndrome }\end{array}$ & 3 & 5 & $\mathrm{~g} 4-6$ & 4.5 & $3-4.6$ \\
\hline $\begin{array}{l}\text { Computer Vision } \\
\text { Syndrome }\end{array}$ & 10 & 11.5 & $8-16$ & 8.4 & $6-11$ \\
\hline $\begin{array}{l}\text { Contact Lens } \\
\text { related }\end{array}$ & 5 & 9.8 & $7-13$ & 7 & $5.2-8$ \\
\hline Environmental & 10 & 9.7 & $6-14$ & 8.4 & $6-12$ \\
\hline Drug induced & 5 & 8.6 & $6-10$ & 8.02 & $7-9$ \\
\hline & & 9 & & & \\
\hline Thyroid disease & 2 & 9 & $8-10$ & 6.5 & $6-7$ \\
\hline Others & 8 & 8.6 & $6-11$ & 5.9 & $2-8$ \\
\hline
\end{tabular}

Findings of study result indicate that significantly low Schirmer's values in patients with Sjogren's syndrome and Steven Johnson syndrome as compared to others.

Similarly TFBUT values are also significantly low in Sjogren's syndrome, Steven Johnson syndrome and dry eye related to meibomian gland disease.

Table 5: Results of TFBUT test in patients with dry eye and normal patients

\begin{tabular}{|l|c|c|}
\hline & \multicolumn{2}{|c|}{ TFBUT (Sec) } \\
\hline & Mean & Range \\
\hline Dry eye subjects & 6.62 & $2-13$ \\
\hline Normal Persons & 10.85 & $6-117$ \\
\hline
\end{tabular}


The comparison of mean score of TFBUT test in normal person and patients with dry indicates that normal person has significantly high TFBUT score as compared to patients with dry eye.

\section{SUMMARY}

Dry eye prevalence in the present study is $16.4 \%$. But, this is a hospital based study which is unlikely to give a true representation of the prevalence of dry eye of the population, as it will be overrepresented.

In our study, dry eye prevalence is more common among elderly i.e, above the age of 50 years, which is consistent with findings in other dry eye studies

Though the difference is not statistically significant, the number of patients developing dry eye is more common in females than males.

In the present study 115 of patients developed dry eye cause of environmental cause. $28.57 \%$ of dry eye patients were noted to be farmers and laborers and $23.33 \%$ of dry eye patients belong to high exposure group(computer operator, driver, salesman, mechanics, field worker, cooks) this explains the fact that these are the person who worked more outdoors and exposed to sun and/or dust developing dry eye.

Dry eye symptoms are not influence by place of residence in our study. Prevalence of dry eye is more in patients with lid related diseases, computer vision syndrome and in those with dry eye because of environmental causes.

Most common symptom reported by the patients was irritation followed by discomfort and foreign body sensation.

Although the Schirmer's test is easy to perform it gives variable results, poor reproducibility and low sensitivity for detecting dry eyes. In our study Schirmer's test result in meibomian gland related dry eye is within range $12-19 \mathrm{~mm}$ with mean $15.18 \mathrm{~mm}$; from this can be inferred that Schirmers test result in meibomian gland related dry eye is towards normal range cannot be used for the diagnosis of meibomian gland related dry eye. In our study normal values for tear film break up time is within 6-17 seconds with mean
10.82 seconds. Tear film break up time in dry eye subjects in our study is within 2-13 seconds with mean of 6.62 seconds.

A limitation of the present study was the exclusion of patients who undergone extra ocular and intraocular surgery leading to an underestimation of dry eye prevalence. Because in such cases it is difficult to interpret dry eye is because of surgery or is present preoperatively and aggravated by surgery.

\section{CONCLUSIONS}

The study with title" Clinical study of Dry eye disease" s carried out in department of Ophthalmology in the tertiary care center Study included total 500 patients which 82 were diagnosed of the disease. Dry eye-is under-diagnosed disorder. Symptoms of dry eye are common in the older population. Dry eye symptoms were more common in female as compared to male. Tear film break up time is very useful test in the diagnosis of dry eye should be used more frequently in the diagnosis and management of dry eye syndrome. Now a day's dry eye seem to occur more frequently in contact lens wearers and computer users and should be taken care of The study reflects a major burden of dry eye disease among the routine outpatients.

\section{LIMITATION OF STUDY}

The study was conducted in the hospital based set up so it doesn't reflact the actual burden of the society.

\section{REFERENCES}

1. The definition and classification of dry eye disease: Report of the Definition and Classification Subcommittee of the International Dry Eye WorkShop (2007). Ocul Surf2007;5:75-92.

2. DE Haas EB. The pathogenesis of keratoconjunctivitis ICCA. Ophthalm-ologica 1964;147:1-18.

3. Ridder WH, Zhang Y, Huang JF. Evaluation of reading speed and contrast sensitivity in dry eye disease. Optom Vis Sci. (3rd) 2013; 90:37-44.

4. Deschamps N, Ricaud X, Rabut G, Labbe A, Baudouin C, Denoyer A. The impact of dry eye disease on visual performance while driving. Am J Ophthalmol. 2013;156:184-189. 
5. Li M, Gong L, Chapin WJ, Zhu M. Assessment of vision-related quality of life in dry eye patients. Invest Ophthalmol Vis Sci. 2012;53:5722-5727.

6. Schiffman RM, Walt JG, Jacobsen G, Doyle JJ, Lebovics G, Sumner W. Utility assessment among patients with dry eye disease Ophthalmology. 2003;110: 1412-1419.

7. American Academy of Ophthalmology Basic and Clinical Science Course Subcommittee.Basic and Clinical Science Course. External Disease and Cornea: Section 8, 2013-2014. San Francisco, CA: American Academy of Ophthalmology; 2013:47-8.

8. Management and therapy of dry eye disease: report of the Management and Therapy Subcommittee of the International Dry Eye Work- Shop (2007).Ocul Surf 2007; 5: 163-78.

9. Reddy M, Reddy P Ranga, Reddy SC . Conjuctival impression of cytology in dry eye states . Indian journal of ophthalmology 1991;39(1):22-24

10. Van Bijsterveld OP. Diagnostic tests in the sicca syndrome. Arch Ophthalmol I 1969; 2: 10-14.

11. Abeitz JM et al Prevelance of dry eye subtypes in clinical optometry practice . Optom Vis Sci 2000;77(7):357-63

12. Omar s Punjabi ; R.s.Adhyanthaya, AD Mhatre, RP JehangirRehumatoid arthritis is a risk factor of dry eye in indian population OpthalmologicalEpedimeol Dec 2006;13(6) 379-384

13. Sukul RR, Shukia Manoj, Nagpal Girish. Tear film break up time in normal Indian subjects. Indian journal of ophthalmology 1 983;31 (4):326- 329. 